Keywords: History, Philosophy, Psychosomatic Psychiatry, Liaison Psychiatry, Psychosomatic Medicine, Subspecialty

\title{
Psychosomatic Psychiatry: a European View
}

\author{
Antonio Lobo* \\ Maximino Lozano** \\ Albert Diefenbacher ${ }^{\star * *}$ \\ * Departamento de Psiquiatría, Hospital \\ Clínico Universitario, Instituto Aragonés de \\ Ciencias de la Salud and Universidad de \\ Zaragoza, Zaragoza, Spain \\ ** Servicio de Psiquiatría, Hospital Ramón y \\ Cajal and Universidad de Alcalá, Madrid, \\ Spain \\ *** Evangelisches Krankenhaus Koenigin \\ Elisabeth Herzberge, University affiliated \\ Hospital of the Charité, Berlin, Germany
}

SPAIN, GERMANY

\begin{abstract}
Background: Consultation-Liaison $(C-L)$ psychiatry, the discipline practiced by psychiatrists working with medical patients, has expanded considerably and the approval as the newest psychiatric subspecialty in the USA has been welcomed. However, the new denomination chosen, Psychosomatic Medicine, has stirred-up controversies in Europe.

Methods: Review of the literature and discussion of historical, empirical and philosophical bases for a new proposal.

Results: We argue that a new denomination is appropriate, and consider the term psychiatry unnegotiable: we are dealing with a specialized area in the psychiatric field, the answer from psychiatry to meet doctors' demands; and the complexity of psychopathological problems presented in medical patients requires specialized experience. Furthermore, contrary to some reductionist, biological views, we consider psychiatry a conspicuous, humanistic medical discipline. We also support the adjective psychosomatic, which reflects the history of the humanistic and scientific 'psychosomatic movement' in medicine. However, the ambiguities surrounding the word should be minimized. Psychosomatic views have been and may still be a stimulus for productive research and for advance in the field, but the excesses of some psychogenetic, non evidence-based theories should be firmly criticized.

Conclusion: We argue strongly in favour of the denomination Psychosomatic Psychiatry for the discipline practiced by psychiatrists working with medical patients, in the intersection with other medical specialities.
\end{abstract}




\section{Introduction}

Consultation-liaison (C-L) psychiatry, or liaison psychiatry has been until very recently the preferred name of the discipline practiced by psychiatrists working with medical patients, fundamentally in general hospitals. The discipline as such was born in the USA, and Lipowski \& Wise $^{1}$ wrote about its history:

"The discipline has developed out of two broad movements, one organizational and the other theoretical. The first one relates to the emergence in USA of general hospital psychiatry, beginning in 1920s; the second one refers to its development at a time when the concept of psychosomatic relationships was capturing both the public and professional imagination(...). The focus of psychosomatic theories was on the role of emotions and psychological states in the genesis and maintenance of organic diseases(...) in this context, consultation-liaison psychiatry became an applied form of psychosomatic medicine"

But C-L psychiatry has evolved considerably during the last decades, to become a psychiatric field fundamentally devoted to psychiatric care of the complex medically ill through consultation and integration with the rest of medicine ${ }^{2}$. Important in the evolution was the movement out of the focus in illnesses such as the 'holy seven', illnesses with histological lesions once believed to have a psychogenic origin. The knowledge about biological, aetio-pathogenic mechanisms involved and effective treatment in these illnesses has improved considerably while, on the contrary, psychogenic theories have been criticized on the bases of insufficient evidence.

However, the main reason for the development of the discipline has been the increasing demand for psychiatry to care for mental disorders in medical settings. Liaison psychiatry is to a good extent the answer from psychia- try to meet doctors' demands. This happens in a context of a sharp increase in all aspects of medical practice in Western countries, and the generalization of health care. Spectacular new diagnostic and therapeutic techniques have dramatically improved life expectancy, although extreme situations also arise as a result of the new developments, which constantly threaten the psychological balance of the individual. It is in this setting that a high rate of psychiatric disturbance in medical patients, and the negative implications of the clustering of medical and psychiatric morbidity, especially in the complex medically ill, has been documented in many studies ${ }^{2}$.

It would be hardly surprising to expect the increasing demand for psychiatry in view of these epidemiological data, but also in view of the positive response of psychiatrists to the challenge. However, C-L psychiatry is both, unsatisfied and quite ambitious about the development of the discipline. While many studies have documented that psychiatric disorders are potentially treatable in the complex medically ill, they are frequently under-diagnosed and under-treated ${ }^{3}$. A large study by the European Consultation-Liaison Workgroup for General Hospital Psychiatry and Psychosomatics documented that only $1.4 \%$ of patients admitted to a general hospital are referred to C-L services, but the conservative estimate of $\mathrm{ECLW}^{4}$ considers that approximately $10 \%$ of admissions require consultation with a psychiatrist. Rather traditional liaison programmes ${ }^{5}$, but also innovative, evidence based intervention models have been developed to face the new challenges, in view of limited resources in psychiatric departments ${ }^{6}$.

To a great extent, C-L psychiatry is an American phenomenon. The US paradigm has been considered to be crucial for the development of the discipline in different countries, including the European countries. 
C-L units have been developed in a considerable proportion of university, but also in nonuniversity hospitals in Europe ${ }^{7}$. For example, the discipline in the UK is already very potent at the clinical level, and they have reported high quality research. In Spain, close to $50 \%$ of the National Health System have now a C-L unit ${ }^{8}$, and C-L is an official rotation in the national residency training programme. C-L Psychiatry has developed considerably in Germany', in a way 'reminiscent of the work of Henry in the US in 1929', and their service delivery is now in general in accordance with international C-L service delivery ${ }^{10}$. However, the German situation is unique, since they have a twostrand medical specialities system, with both, psychiatrists and psychosomaticists doing consultations in the general hospital.

"Consultation-liaison psychiatry services are pro-
vided in virtually all German general hospitals,
mainly by the medical specialty of psychiatry and
psychotherapy and to a lesser extent by the spe-
cialty of psychosomatics and psychotherapeutic
medicine, exclusively so in 5\%. The latter spe-
cialty includes non-psychiatric physicians"

Recent, international reports highlight how the discipline is rapidly and appropriately expanding, and new areas of development include primary care, but also the fields of genetics, clinical ethics, and endof-life care. C-L psychiatry is served by a number of national specialized organizations in the USA, but also in European and other countries and there are international organizations. It may also be proclaimed the C-L psychiatry is now a specialized body of scientific knowledge regarding psychiatric aspects of medical illness ${ }^{11}$. This knowledge has been collected in a number of contemporary textbooks, medical and psychiatric journals, and regularly reported in international, scientific meetings. C-L psychiatry needs a very specialized training at the medical illness-psychiatry interface, but this may now be provided by a cadre of clinicians, scholars and researchers that has emerged notoriously in different countries.

The time seemed ripe for sub-specialization in the field ${ }^{12}$. Some psychiatrists have expressed concerns about potential negative outcomes, such as the fragmentation of the field, weakening of generalists, increasing cost of care, or even the undermining of core graduate education $^{13}$. However, the existing, significant body of scientific knowledge and research makes it difficult for the generalist to stay abreast of developments in most areas. Consequently, the approval in 2003 by the American Board of Medical Specialists of C-L Psychiatry as the newest psychiatric subspecialty has to be welcomed ${ }^{14}$. Most would agree with Lyketsos ${ }^{2}$ :

"Formal recognition as a subspecialty in the US has and will strengthen PM and will enhance its growth internationally. The certification of more psychiatrists with expertise in PM will help address the unmet psychiatric needs of the medically ill, improve the quality of education and training both in psychiatry and in other areas of medicine, promote integrative research, and improve the medical outcomes of this complex patient population".

The new denomination, Psychosomatic Medicine, was chosen 'to return to the name for the field imbedded in its history, its journals, and its national organizations'2. However, the name has stirred up some controversies, as McIntyre ${ }^{15}$ had anticipated. In fact, while C-L psychiatry and psychosomatic medicine have common roots and have evolved simultaneously in the history of psychiatry, the review of the literature suggests they are not identical ${ }^{16}$. The denomination of this subspecialty has been debated for years, and the other names previously considered, which emphasize different aspects of its orientation, also present many difficulties. The list includes names such as Behavioural Med- 
icine, Psychological Medicine, General Hospital Psychiatry, Medical-Surgical Psychiatry and Psychiatry of Primary Care.

We believe the question of the name for the discipline is not unimportant. Should we now support the new American name? It would certainly facilitate trans-national communication. In European countries, the term Liaison Psychiatry has been gaining favour over the last decades, following mainly the American trends ${ }^{7,10}$. But in fact, the new American denomination has stirredup some controversies in Europe. On the bases of the extended opinion that 'all medicine should be psychosomatic' 17 , many non-psychiatrists state they also practice 'psychosomatic medicine'. From the C-L field, Rigatelli et al. ${ }^{18}$ in Italy have been very vocal about the critiques, since 'the relationship between psychosomatic medicine (PM) and C-L psychiatry (CLP) is still controversial, both in a theoretical perspective and in its pragmatic implications':

Obviously, historical and cultural reasons are at issue here, which might help understand Rigatelli et al's discouragement. But historical and cultural reasons certainly have to be also considered in other European countries, particularly in Germany, where strong tensions still exist partially due to the large overlap between the two medical disciplines involved in this field ${ }^{19}$.

"The reader will have to learn a lot about the eminent role that historical developments and tradition, in contrast to evidence-based medicine, still play in Germany in the shaping of the care for psychologically ill patients in general and those with physical/psychiatric co-morbidity in particular" $"$.

In Spain, the official name is Liaison Psychiatry. However, its use has not become established among our medical colleagues, probably because unlike the terminology that is normally implemented for medical special- ities, it is imprecise and does not sound very clinical. After much debate with colleagues throughout the last few years, Lozano ${ }^{20}$ was the first to argue in favour of the denomination Psychosomatic Psychiatry for the discipline. McIntyre ${ }^{15}$ has also suggested the name, and some of us have strongly supported this denomination ${ }^{21}$.

A reappraisal of the bases for this proposal may now be summarized as follows.

\section{The term psychiatry is unnegotiable}

We consider the term psychiatry un-negotiable, it should be maintained in any future name of the discipline. The arguments in favour of this position are the following:

\section{We are talking about a subspecialty of Psychiatry}

Whatever the name of the discipline is used, we are talking about a subspecialty of Psychiatry. For example, Wise \& Rundell ${ }^{22}$, the editors of the previous edition of the American Psychiatric Publishing, Inc, text of the discipline called it Textbook of Consultation-Liaison Psychiatry. The statement of the editors in the preface is quite clarifying:

"We believe that long-established principles of CL psychiatry hold the key to psychiatrists' continued status as physicians and as a part of the medical field. These principles view the psychiatrist as 1) an expert in the mental status examination, 2) knowledgeable about medical conditions and treatments, 3) able to communicate with other physicians in the vocabulary and metaphors of medicine, 4) skilled at forming a comprehensive biopsychosocial differential diagnosis, 5) comfortable in working with medical-surgical colleagues, 6) skilled in both psychopharmacology 
and psychotherapy, 7) cost-effective, and 8) able to work in a variety of different and even unique medical and surgical settings"

Similarly, Psychosomatic Medicine, the heir of C-L Psychiatry in USA, is defined in the new text ${ }^{23}$, which is expected to be the standard in the discipline, as:

"A specialized area of psychiatry whose practitioners have particular expertise in the diagnosis and treatment of psychiatric disorders and difficulties in complex medically ill patients" ${ }^{\prime 4}$.

Therefore, a new psychiatric subspecialty should incorporate the name psychiatry, as is the case in other subspecialties both, in the USA and in European countries: Child and Adolescent Psychiatry, Geriatric Psychiatry and so on. This would contribute to harmonize denominations in our specialty.

\section{C-L psychiatry or liaison psychiatry is the answer from psychiatry to meet doctors' demands}

The history of the discipline in the USA shows how the field started to grow very early, since Henry's years, when psychiatrists were called by medical colleagues to solve an increasing number of problems of their expertise'. The so called 'psychosomatic movement' certainly provided fuel for the enthusiasm of early day clinicians. But the psychiatrists were able to modify their position and their practice to adapt to the real clinical situation ${ }^{18}$; to teach students in the same direction; and to develop and implement clinical research studies to solve the most frequent problems in their clinical practice. This included the development of liaison programs to meet the needs of different medical services and, in more recent years, to successfully face the challenge of the management revolution.
Similar developments took place more recently in European countries such as Germany, Italy and Spain and also in other continents $7,9,24,25$. It has been shown different times how consultations increased by the day as soon as C-L units started their function. It was psychiatry the discipline assigning a considerable slot of its resources to take care of clinical problems in medical departments. Many physicians, internists in particular, were interested in the so called psychosomatic movement in the last century. However, with the exception of Germany and to some extent some German speaking countries, no medical discipline but psychiatry has vigorously extended its development to become specialized in clinical problems related to the psyche-soma relationships. In fact, and unfortunately, in countries such as Spain non-psychiatrists have almost disappeared in psychosomatic forums of the highest scientific level.

\section{The severity and complexity of psychopathological problems presented in medical patients requires specialized psychiatric experience}

Lyketsos et $a .^{2}$ have brightly summarized the type of patients and clinical problems confronted nowadays by practitioners in our discipline:

“(...) four general groups of patients, sometimes referred to as the 'complex medically ill': those with co-morbid psychiatric and general medical illnesses complicating each other's management; those with psychiatric disorders that are the direct consequence of a primary medical condition or its treatment, such as delirium, dementia or other secondary mental disorders (formerly known as 'organic' disorders); those with complex illness behavior such as 'somatoform' and functional disorders; and, patients with acute psychopathology admitted to medical-surgical 
units, such as after attempted suicide. Many of these patients have multiple medical, psychiatric, functional, and/or substance abuse disorders, thus are best thought of as the psychiatric counterpart of the multimorbid frail elderly seen by geriatricians".

This statement very clearly approaches what the ECLW ${ }^{4}$ has documented to be the most common ICD-10 diagnostic categories referred to C-L psychiatry in European hospitals: organic disorders; complicated, substance abuse disorders; and major depressive disorders. Cases of complex illness behavior and adjustment disorders are also frequently referred, but the co-morbid psychopathology in such cases is often part of very complex clinical pictures. The organicity and/or the severity of psychopathological problems in the first three categories; and the complexity of cases in all categories with co-morbid somatic and psychopathological disorders mean that C-L psychiatrists are often confronting quite serious and unique clinical problems at the interface of psychiatry and medicine.

In fact, not all psychiatrists are prepared to work in this field. Throughout the years, only psychiatrists with an special interest and vocation to work in general hospitals have acquired considerable experience to face the complex clinical needs in this setting. However, they also need a very specialized training. Levenson's ${ }^{23}$ textbook adequately reflects the scientific status in our discipline nowadays. In the USA, by the 1980s, all psychiatry residency programs were required to provide substantial clinical experience in the field, and subspecialty fellowship training has been available for over 25 years. Following this lead, specialized training is also offered now in other countries, including some European countries ${ }^{7}$.

\section{Psychiatry is a humanistic, medical discipline}

Surprising as it might appear, the true fact is that psychiatry is identified solely with strict biological methods and paradigms in some European 'psychosomatic' environments, particularly in one of the strands in the German system ${ }^{9,26}$. Therefore, both the name and the discipline are not necessarily welcomed in such environments. U. Malt ${ }^{19}$ has expressed that clearly:

\begin{abstract}
"There are still strong feelings about this issue in Germany. Some psychotherapists ('psychosomaticists') sincerely have the opinion that psychiatry is -and always will be-a biological discipline solely using biological treatment methods. Some even purport the view that current German psychiatry is only a continuation of the Eugenics of the Nazi period with its emphasis on biological deviance and 'unworthy life'. This is of course not true. However, in the view of those persons, psychosomatic medicine is the humanistic (or psychotherapeutic) alternative to psychiatry. The fact that those opinions are purported even at the beginning of the $21^{\text {st }}$ century tells us something about the strong tensions that still exist in psychological medicine in Germany".
\end{abstract}

For American psychiatry, traditionally influenced by psychoanalytic views and later on by Engel's ${ }^{27}$ biopsychosocial model, the German critiques might be difficult to understand. They are also difficult to understand in other European countries, such as Spain, since humanism in psychiatry has a long tradition. In fact, the influence of great philosophers and thinkers, certainly philosophers of German origin, was crucial to maintain from the beginnings of academic psychiatry in Spain, in the $20^{\text {th }}$ century, humanistic, holistic, 'anthropological' views:

"It was from this time on that the impact of philosophers such as Kant, Kierkegaard, Nietzsche, Dilthey, Bergson, Buber and Heidegger came to be felt, and man as an object of study was rediscovered. Spanish philosophers such as 
Ortega y Gasset, Zubiri, and Unamuno are credited with introducing and developing these views" 25 .

But the influence of humanistic views in academic psychiatry has to do not only with traditional medical practice going back to the times of Hypocrates. It has to do also with strict scientific positions. The great exemplar of such views is Karl Jaspers, and his influence is widely acknowledged in academic psychiatry, certainly in Spain ${ }^{25}$. From the European perspective, it is quite relevant to look at the position of the influential British psychiatry, which might be adequately reflected in Shepherd's foreword to the Cambridge University Press textbook ${ }^{28}$. This book was intended to be...

"(...) a representative statement of what has been termed the 'Maudsley' approach to psychological medicine. Modern British psychiatry, as Lord Taylor has pointed out, is 'largely the product of the Maudsley Hospital'. It embodies not so much a national school of opinion as a continuation of the broad, central tradition of psychiatric theory and practice which originated on the European main land, was transported through the psychobiology of Adolf Meyer to North America and returned to Europe via the United Kingdom, where its pre-eminent representative has been $\mathrm{Sir}$ Aubrey Lewis".

The influence of Jaspers is quite explicit in the textbook:

"The subject-matter of this volume develops the map charted by Karl Jaspers in his General Psychopathology, which remains the clearest and most convincing outline of the whole field ${ }^{29}$. Jaspers nowhere provides a clear-cut definition of psychopathology, and points out that its "essence (...) as a study can only emerge from a composite framework". Inveighing against the futility of 'endlessness', the attempt to establish absolute knowledge through the application of any one scientific discipline, he urges the psychiatrist to "acquire some of the view-points and methods that belong to the world of the Humanities an Social Studies (...) since the methods of almost all the Arts and Sciences converge on psychopathology". With this ambiguous phrase Jaspers indicates the complex nature of a discipline which, in his view, extended the notion of scientific enquiry as it is usually understood" 28 .

Here we have the influential jasperian, clear psychiatric position against narrow, reductionist biological views in psychiatry. Not only that. Jaspers made crucial statements about the scientific role of humanities in psychiatry.

"While claiming scientific status for psychopathology he also asserts that 'Science is wrongly identified with Natural Science (...) natural science is indeed the groundwork of psychopathology and an essential element in it but the humanities are equally so and, with this, psychopathology does not become in any way less scientific but scientific in another way (...)" "(...) In sum, then, Jaspers enlarges the field of general psychopathology to extend from the natural sciences, and in particular biological science, via descriptive phenomenology to existentialist philosophy. The psychopathologist employs the scientific method and the scientific attitude even when dealing with phenomena like subjective experience or meaningful connection, but his own position is ultimately non-reductionist and transcendental" 28 .

In fact, Jasperian influence in key American centres such as Johns Hopkins is also quite explicit, both at the scientific level and from the humanistic point of view ${ }^{30}$.

“(...) The great exemplar is Karl Jaspers, who combined the rationalism of modernity (expressed in the standards of psychiatric assessment) with the central contribution of postmodernism, phenomenology. He produced the fist coherent study of methods of psychiatric reasoning that emphasized their strengths, their weaknesses, and their apt employment(...)" “(...) In such a way he could acknowledge the numinous aspects of human nature -far more profoundly than the antimodernists- even as he resolved misunderstanding that have led to the conflicts, indeed imperialist wars, between modern and postmodern psychiatry. His conception of psychiatry rested critically on several features of his work: his defense of the 
study of the psyche in many different ways, his commitment to science where science is appropriate, and his defense of human beings as fundamentally free and radically mysterious (...) ${ }^{, 30}$.

$\mathrm{McHugh}^{31}$ has proposed four standard methods or 'perspectives' for psychiatry which, in combination, try to provide a basic structure for psychiatry. We have previously argued in favour of the usefulness of this model in liaison psychiatry ${ }^{32}$. Jasperian influence in the model is quite apparent: while the 'disease perspective' to be used for example in organic disorders requires 'explanation' (Erklärung), the 'life story perspective' requires the 'understanding' (Verstehen) to be used in adjustment and similar disorders we see in general hospital patients. Humanistic philosophy is at the heart of this last 'perspective'.

"Finally, the life-story perspective rests on the logic of narrative. A distressed state of mind can be the natural, quite understandable, result of a disturbing experience. Grief is an emotional expression of loss, fear often follows a traumatic misadventure, and demoralization is a result of a discouraging interpretation of life circumstances. A narrative -a chronological recounting of settings, sequence, and outcome- can make the evolution of these emotional states comprehensible to patient and physician alike. The therapeutic implications tied to this perspective include the need to comfort and guide patients through a natural course of recovery, to assist them in appreciating how they can act to avoid similar encounters in the future, and to provide more optimism and effective action (...),30.

\section{In support of the adjective psychosomatic}

\section{Introduction}

We support the inclusion of the adjective 'psychosomatic' in the denomination of the subspecialty. We believe it reflects the field's history, in particular the holistic, humanistic and anthropological spirit of the so called 'psychosomatic movement'; and psychosomatic theories have stimulated and should stimulate empirical research in clinical populations where the coexistence of physical and psychopathological phenomena is paramount. However, there is much debate about the use of this adjective, and we should be aware of the ambiguities of the term and the harsh critiques it has stirred up from the field of empirical research.

\section{The so called 'psychosomatic movement' has been both, a humanistic and a scientific movement}

The protests of clinicians and some philosophers about the tendency to identify psychiatry solely with strict biological paradigms reached the field of general medicine. Early in the $20^{\text {th- }}$ century the traditional interest of physicians in humanistic, holistic medicine was again apparent ${ }^{17,33}$. The term holistic medicine covers an enormous variety of theories of illness and methods of healing ${ }^{34}$. However, at the heart of the concept underlies the idea that the biomedical view is both, much too constricted and insufficient to help patients.

"To the holistic oriented, the biomedical view is much too constricted. (...) the biomedical view excludes a realm of human experience that, by supplying meaning to life, contributes importantly to a sense of well-being. Furthermore, by concentrating on the body, it neglects all the voluntary behaviours that can affect health (...). As a result, despite the dramatic successes of the biomedical approach in curing many illnesses, it falls down badly with respect to the other mission of medicine, which is to preserve health (...). From a public health standpoint, the record of biomedical medicine is scarcely something to be proud of 34 . 
Such humanistic views also have a scientific side. Medical historians have done splendid work in showing that in the period between the two world wars, some influential authors in European countries reflected the feeling that the individual was being lost as an object of scientific study, despite the splendor and achievement of scientific medicine based on the naturalistic $19^{\text {th }}$-century model $^{25}$. In Spain, Krehl, an internist in Heidelberg, is credited with having introduced 'anthropological views', especially through his disciples, Siebeck and von Weizsäcker. The principles of 'anthropological' medicine were also important in the development of the so called 'psychosomatic movement', which has provided the fuel for more recent developments ${ }^{35,36}$.

In this context, Engel's ${ }^{27}$ encompassing, 'biopsychosocial' model, has been enthusiastically endorsed by many ${ }^{32}$. It derived from the 'psychobiology' Adolf Meyer proposed at the Johns Hopkins Hospital in the 1950 's and is coherent with the holistic approach and with the spirit that is often identified with the adjective psychosomatic. We certainly would like to preserve this spirit. Even critical writers acknowledge many features to recommend encompassing models such as the biopsychosocial one ${ }^{31}$. But the advocacy of encompassing models in our field should not be obstacle to be alert about their limitations. Ambiguity and lack of limits in the definition is one of the problems:

\footnotetext{
"The term holistic medicine covers an enormous variety of theories of illness and methods of healing. It has been applied to humanistic medicine, psychosomatic medicine and behavioural medicine. Its methods cover a similarly wide range, from the mundane such as diet, exercise, relaxation and massage through the more elaborate such as biofeedback to the exotic such as acupuncture and Arica training. Finally, many proponents of the holistic approach also advocate mobilizing healing spiritual forces through meditation and prayer" ${ }^{\prime 34}$.
}

A review of the literature suggests that some European thinkers, supporters of 'monistic', unitary, 'anthropological' views are quite critical of American views on the psychosomatic approach, considered to be 'dualistic' 25 . In fact, international views in the psychosomatic field vary widely ${ }^{37}$. From the scientific point of view, it might be rightly argued that a holistic approach in psychopathology has not been adequately resolved. Philosophers of science are dealing with concepts such as transcendentalism, emergent biology ${ }^{38}$ or non-reductive materialism ${ }^{39}$ to reduce this gap in knowledge. The complexity of the task should deter the proponents of simplistic, unsupported 'psychosomatic' theories we discuss in later sections of this article.

Critiques from the empirical point of view reach encompassing models such as the 'biopsychosocial model': it may be considered to be so broad in its scope and so non-specific in its relations to any particular disorder that it may be 'heuristically sterile' ${ }^{31}$. Critiques also come from the clinical, pragmatic point of view. While monistic views about human nature in both health and disease may have philosophical support and be ideals to keep in mind, they are difficult to put into practice. An encompassing model may be an empty phrase, unless it gives specific guidelines ${ }^{40}$.

\section{Psychosomatic views have been and may be a stimulus for research}

Even though psychosomatic theories, in particular psychogenetic theories have been severely criticized on the bases of lack of empirical evidence, there is little doubt that they have stimulated research in the field. 
The comments by Shepherd ${ }^{41}$ were particularly bitter in relation to psychogenic views:

"(...) So cavalier disregard for the complexities of the mind-body relationship and the nature of causality could only have been taken seriously in the climate of opinion then prevailing. In retrospect it is apparent that much of what passed for psychosomatic medicine was little more than a scientifically naïve attempt to impose psychoanalytical theorizing on physical illness in an attempt to demonstrate psychological causation. Since then the undermining of these high hopes by intensive clinical and experimental investigation has led Grinker to conclude that "The concept of a psychosomatic disorder is fast becoming obsolete (...)" and Lewis to remark that the term reflects only a rather muddled phase of specialized ignorance".

In the humanistic climate of the psychosomatic movement, it is apparent that his proponents adopted methods close to the 'life story' perspective as the primary way of comprehending a state of distress. But $\mathrm{McHugh}^{31}$ has alerted about some risks of the method:

"This method (...)(adding ingredients from the dynamic unconscious if needed) can promote therapeutic optimism and confidence in both the patient and the psychiatrist' (...) and is 'the major basis of psychotherapy'(...) "For some, the life story perspective contains the warp and weft of psychiatric practice" (...) "A missionary fervour, however, may develop around the story method".

We suspect some proponents of psychogenetic theories developed a kind of missionary fervour, particularly in view of the apparent disregard for the psychological aspects of medical practice they found among some medical colleagues. It was uncritical fervour, rather than evidence based positions which did much to discredit the discipline ${ }^{25}$. Nevertheless, while critiques of psychogenetic theories of the 50's and 60's were generally well supported, even critical reviewers have concluded that "(...) much useful information has been obtained (and will continue to be obtained) by applying both psychological and physical methods to medical problems (...)"42. Specialized publications such as the Journal of Psychosomatic Research and recent textbooks ${ }^{23}$ are witnesses of a broad field of solid knowledge accumulated by now, which is out of the scope of this article to review.

From the epidemiological view, Shepherd ${ }^{41}$ also criticized psychogenetic theories:

"(...) they have also obstructed the application of the epidemiological perspective by deflecting interest away from the wider application of the mid-body nexus in the various forms of recognised mental disease (...). A psychogenic factor is only one link in a multifactorial chain(...)".

We have also argued strongly about the potential of epidemiological methods in this field to increase knowledge and to improve the quality of clinical practice ${ }^{43}$. We have concluded that substantial evidence is now available coming from all the most conspicuous epidemiological methods: the completion of the spectrum of disease; the establishment of outcome; the actuarial assessment of morbid risk; the evaluation of the efficacy of treatment; and the conceptual construction of diagnosis and classification. Specialized reviews support these conclusions ${ }^{44}$, and we believe the knowledge is to some extent the result of testing hypotheses of clinicians and thinkers advocating psychosomatic views in medicine. But in writing about the potential of research in the field, the ambiguities surrounding the definition of the word psychosomatic need immediate consideration.

\section{The ambiguities surrounding the concept of the term psychosomatic may and should be minimized}

Medical historians have done splendid work in tracing the origin of the word psy- 
chosomatic. The term -from the Greek psyche (soul) and soma (body)- was coined first in German by J. C. A. Heinroth (1773-1843), and popularized by Jacobi (1775-1858). It originally meant simply 'belonging both to mind and body'. However, the Greeks and other ancient cultures did not require a specific word to distinguish between psychic and somatic components of an illness although they had separate notions for mind and body, since their view of patients was rather holistic. This tradition of what has been termed 'holistic medical materialism' of Hypocrates and Galen dominated scientific thought for centuries, but things changed under the crucial influence of Descartes: while the new directions in scientific thought stimulated the advance of knowledge, the excesses of mechanistic and materialistic views in medicine were soon apparent $\mathrm{t}^{45}$ :

“(...) Descartes, a devout Christian, sharply demarcated the immaterial, immortal soul (or mind) from substantial, extended matter, the latter being the proper subject of science. His considerable influence extended to eighteenth-century mechanists and materialists like D'Holbach (1723-89) and La Mettrie (1709-51) (...) The powerful persuasiveness of pathology encouraged eighteenthand nineteenth-century alienists to posit physical models to explain mental disturbances (...),46.

The need for the new term psychosomatic "derives largely from the power acquired by somatic pathology since the seventeenthcentury mechanization of the world picture". It means an attempt "to circumvent certain polarities -mind-body, spirit-matter, subjective-objective- which are firmly enshrined in modern scientific thought" 46 . Because historians have also shown that physicians, if not ordinary men, always observed the mutual influence of mind and body ${ }^{17,33}$.

\footnotetext{
“(...) and even Descartes, especially in his discussion of the passions (a word earlier used in roughly the same sense as we now use 'emotions') sought to relate strong feelings like jeal-
}

ousy or love to physiological changes. Doctors were perennially exposed to this phenomenologically two-way traffic: "the reason why a sound body becomes ill or an ailing body recovers may lie in the mind. Contrariwise the body frequently both begets mental illness and heals its offspring" (...)" ${ }^{, 46}$.

The original meaning of the term psychosomatic, 'belonging both to mind and body', has later been extended after the observations of classical authors such as Cabanis, Charcot, Lange, etc., which led the ground for theories of the relationship between the external precipitating events, physiological reactions, and subjective feeling states. These theories eventually became the starting point for twentieth-century conceptions of so called 'psychosomatic disorders'. 'Stress' and the 'emotions' were initially the most commonly studied factors in psychosomatic investigations following observations of authors such as Cannon, but many other methods were eventually used, including psycho-physiological, individual life histories, anthropological, epidemiological and, certainly, psycho-analytical methods.

The term psychosomatic was again popularized after the First World War, by a group of German and Austrian psycho-analytically oriented psychiatrists, notably F. Deutsch, G. Groddeck, E. Wittkower and F. Alexander. These workers emphasized the need to consider patients as psychosomatic units and saw danger in perpetuating the concept of a mind-body dichotomy. Many pioneers of the psychosomatic movement left Europe in the 1930's to work in the USA where they developed their ideas with American psychiatrists such as Flanders Dunbar. At this time, the word became frequently employed to refer to a cluster of disorders in which the emotions were considered to play a fundamental aetiological role and the involved organ is usually under autonomic nervous system innervations: asthma, hypertension, peptic ulcer, etc. 
The field of study has gradually expanded over the past fifty years, but the elasticity of the term has some risks. Much useful information has been obtained (and will continue to be obtained) by applying both psychological and physical methods to medical problems, but the uncritical application of the methods has led to untenable psychogenetic positions. The original meaning of the term, relating to a holistic approach to medicine has always been maintained to a certain extent, and is accepted by most authors. On the contrary, the second use of the adjective 'psychosomatic', referring to particular disorders in which psychological factors are supposed to play a major role', is very controversial, and has led to confusion. The World Health Organization ${ }^{47}$, called a 'psychosomatic paradox' the double use of the term, and some writers have suggested that 'it seems possible that the word 'psychosomatic' has outlived its usefulness' ${ }^{42}$.

We suggest we should stick to the original meaning of the term psychosomatic, 'belonging both to mind and body', and consider acceptable Lipowski's ${ }^{48,49}$ proposition.

"The term psychosomatic refers to the postulate that mind and body are two inseparably linked aspects of man which are distinguished for methodological and communicative purposes only. This connotation of the word may be called 'holistic', in that it implies a view of the human organism as a whole, a mind-body complex. The term is not meant to imply causality, that is to say, that the psyche is somehow the cause of somatic events. On the contrary, it implies that the human organism, or the person, invariably functions, reacts, and acts as an integrated mindbody unit"49.

In relation to this, we suggest that the concept psychosomatic disorder, commonly seen in the medical and psychiatric literature is both, ambiguous and weak ${ }^{50}$, and some authors have argued it should be abandoned $^{49}$. To our knowledge, there is not a convincing conceptualization of this name, and we suggest it should be questioned. A detailed discussion of this point is out of the scope of this paper, but the main reasons may be summarized as follows. First, if we accept the holistic meaning of the term, all medical disturbances are to some extent 'psychosomatic'. Second, for the sake of precision, we suggest the word psychogenic should be used if what we mean is a psychological causality of somatic illness. Of course, the supporters of such statement should be prepared to offer evidence about the existence of both necessary and sufficient causes. Third, and finally, we have previously discussed how groups of disorders sometimes called 'psychosomatic' come from quite heterogeneous categories, classified in quite different categories of international, psychiatric classifications (including both ICD-10 and DSM-IV) ${ }^{50}$ : somatized, endogenous/melancholic depressions; somatization disorders; neurovegetative, somatoform disorders; and certainly, the somatic illnesses such as asthma, peptic ulcer, etc. pertaining to the so called 'holy seven'. It is quite difficult to find a common denominator for all these disorders.

On the other hand, the name psychosomatic medicine has a wide use, but there is no international agreement on how to define the concept. In countries such as Spain is fundamentally used referring to a holistic approach, all medicine should be psychosomatic $^{17,25}$. However, its conceptualization may be particularly confusing to external observers in Germany. In this country, and to some extent in some German speaking countries, three different definitions are used in a context of strong tensions, as described by Malt ${ }^{19}$ and Diefenbacher ${ }^{10}$ : psychosomatic medicine defined as "biopsychosocial or holistic medicine"; as "psychological conflicts causing physical dysfunction and 
disease"; or defined simply as 'psychotherapy'. In this context, the American denomination for the new subspecialty, the heir term for C-L psychiatry, may add some confusion. We believe the previous proposal by Lipowski and Wise ${ }^{1}$ may be acceptable:

"Psychosomatic medicine is a discipline concerned with 1) the study of the correlations of psychological and social phenomena with physiological functions (normal or pathological) and the interplay of biological and psychosocial factors in the development, course and outcome of all diseases and 2) advocacy of a biopsychosocial approach to patient care. However, psychosomatic medicine is not an organized specialty of medical care, whereas consultation psychiatry is such a subspecialty".

In other words: we support the classical concept of psychosomatic medicine close to a holistic view; and broad enough to support the clinical use and the study of a broad field of correlations of psychological and social phenomena with physiological functions in medical illness. In this context, we consider that the new denomination we support for the subspecialty, psychosomatic psychiatry, is quite adequate to reflect what we argue it should be: a psychiatric contribution to a holistic, psychosomatic medicine. We further consider that there is no other single adjective to include in the name of the subspecialty which so well reflects its meaning.

\section{Should the term liaison be abandoned?}

Consultation-liaison (C-L) psychiatry, or liaison psychiatry, the preferred name of the discipline until very recently, has not resisted the test of time in the USA, precisely in the country of its birth and most successful development. Under the influence of Amer- ican colleagues, this previous denomination extended internationally, also in European countries $^{7}$. It has also influenced German terminology ${ }^{10}$. In Spain, liaison psychiatry has been the official name in different organizations, including some clinical programmes in the National Health System, the teaching programme of the National Commission for the specialty of Psychiatry and the National Research Network of the Instituto de Salud Carlos III $I^{51}$. However, this denomination has not become well recognized among medical colleagues.

We support a new name for the subspecialty. However, we are also alert about obstacles and challenges ahead in implementing new denominations. Furthermore, we are not prepared to abandon the term liaison to refer to clinical, teaching and management programs of collaboration of psychiatrists and non-psychiatrists in medical settings, following schemas implemented during the last decades ${ }^{5}$.

\footnotetext{
"Most PM psychiatrists are on psychiatric consultation services, rarely found outside teaching hospitals, and their services are reactive, typically emergent or urgent. Optimal care for patients with complex medical illnesses (...) calls for close working relationships with the primary physicians as well as easy access to specialized psychiatric expertise. Psychiatric liaison, in which psychiatrists are integrated members of a specialized care team, is a more advanced model, with greater ability to provide early detection and prevention"2.
}

This is also compatible with the incorporation of new plans for the discipline, such as the so called 'integrative models'. In fact, we support the search for new models, such as the models related to the 'medicine-psychiatry' inpatient units ${ }^{52,53}$ and other integrated service delivery approaches ${ }^{54,55}$. 


\section{Final comments}

We here suggest a new denomination for a new psychiatric subspecialty, Psychosomatic Psychiatry: the psychiatric contribution to the broad field of psychosomatic medicine. Nevertheless, we can not claim exclusivity, and progress in the field and its contributions to care are endangered by existing splits and fragmentation in health care delivery and financing. From a European perspective, Söllner ${ }^{36}$ has discussed different models, partially overlapping with American ones. With regard to the twostranded C-L service delivery that exists in some general and university hospitals in Germany, Malt has discussed both advantages and disadvantages ${ }^{19}$. In fact, the contribution to the field from the non-psychiatric medical specialty called 'Psychosomatic Medicine and Psychotherapy' has been very substantial. It is not well known perhaps that 8,000 inpatient beds are maintained by these psychosomaticists, physicians derived somehow from the internal medicine field ${ }^{26}$. Diefenbacher ${ }^{10}$ has suggested that there is no empirical evidence for the objective assessment of the advantages and/or shortcomings of the German, two-stranded system. However, on the basis of his experience, he argues that " (...) it cannot, due to its special history, and should not, for conceptual and pragmatic reasons, be emulated in other countries".

\section{Acknowledgements}

Supported by grants from the Fondo de Investigación Sanitaria, and the Spanish Ministry of Health, Instituto de Salud Carlos III: RETICS RD06/0011(REM-TAP Network) and G03/128 (REPEP Network).

\section{References}

1. Lipowski ZJ, Wise T N. History of Consultation-Liaison Psychiatry. In Wise M G, Rundell J R, (eds.) Textbook of Consultation-Liaison Psychiatry: The Practice of Psychiatry in the Medically Ill. Washington: American Psychiatric Publishing; 2002. p. XV-XVI.

2. Lyketsos CG, Huyse FJ, Gitlin DF et al. Psychosomatic medicine: A new psychiatric subspecialty in the u.s. focused on the interface between psychiatry and medicine. Eur J Psychiat 2006; 20(3): 165-171.

3. Kornfeld DS. Consultation-Liaison psychiatry: contributions to medical practice. Am J Psychiatry 2002; 159: 1964-1972.

4. Huyse FJ, Herzog T, Malt UF, Lobo A. The European Consultation-Liaison Workgroup (ECLW) Collaborative Study. I. General outline. Gen Hosp Psychiatry 1996; 18(1): 44-55

5. Strain J. Liaison Psychiatry. In Wise M, Rundell JR (eds.) Textbook of Consultation-Liaison Psychiatry. Psychiatry in Medically ill. $2^{\text {nd }}$ Edition. Washington, DC: American Psychiatric Publishing, Inc.; 2002. p. 33-48.

6. Huyse FJ. From consultation to complexity of care prediction and health service needs assessment. J Psychosom Res 1997; 43(3): 233-240.

7. Huyse FJ, Herzog T, Malt U, et al. International Perspectives of Consultation Psychiatry. In Wise M, Rundell JR (eds.) Textbook of Consultation-Liaison Psychiatry. Psychiatry in Medically ill. $2^{\text {nd }}$ Edition. Washington, DC: American Psychiatric Publishing, Inc.; 2002. p. 203-233.

8. Campos R, Iglesias C, Zabala I, Lozano M. Present state of C-L Psychiatry in Spain Paper read at the $3^{\text {rd }}$ Annual Scientific Meeting of the European Association of Consultation-Liaison Psychiatry and Psychosomatics; 2000 june 16-21; Oslo, Norway.

9. Diefenbacher A (ed.) Consultation-liaison psychiatry in Germany, Austria, and Switzerland. Basel, New York: Karger; 2004. (Advances in psychosomatic medicine; vol. 26)

10. Diefenbacher A. Psychiatry and psychosomatic medicine in Germany: lessons to be learned? Aust N Z J Psychiatry 2005; 39(9): 782-794.

11. Lyketsos CG, Levenson JL. Academy of Psychosomatic Medicine (APM) Task Force for Subspecialization: Proposal for recognition of 'Psychosomatic Medicine' as a psychiatric subspeciality. Academy of Psychosomatic Medicine 2001.

12. Yager I. Subspecialization in psychiatry. In Yager I. (ed.) The Future of Psychiatry as a Medical Specialty. Washington DC: American Psychiatric Press; 1989. p. 33-47. 
13. Romano J. Reminiscences: 1938 and since. Am J Psychiatry 1994; 151 (6 Suppl): S83-S89.

14. Gitlin DF, Levenson JL, Lyketsos CG. Psychosomatic medicine: a new psychiatric subspecialty. Acad Psychiatry $2004 ; 28(1): 4-11$.

15. McIntyre JS. A new subspecialty. Am J Psychiatry 2002; 159(12): 1961-1963.

16. Lipsitt DR. Consultation-liaison psychiatry and psychosomatic medicine: the company they keep. Psychosom Med 2001; 63(6): 896-909.

17. Lain Entralgo P. Mind and body. Psychosomatic pathology. Trans. Espinosa, AM. London: Harvill; 1955.

18. Rigatelli M, Gritti P, Ferrari S, Di Caprio EL. The relationship between Psychosomatic Medicine and Consultation-Liaison Psychiatry: an ongoing problem.. World Psychiatry 2004; 3(S1): S17. [abstract] Paper read at the World Psychiatric Association International Congress in Florence 10-13 November 2004. Treatments in Psychiatry: an update

19. Malt UF. German Psychosomatic Medicine: An international perspective. In Diefenbacher A (ed.) Consultation-liaison psychiatry in Germany, Austria, and Switzerland. Basel, New York: Karger; 2004. (Advances in psychosomatic medicine; vol. 26). p. 196-202.

20. Lozano M. Un nombre para la conceptuación y la práctica de la medicina psicosomática y la psiquiatría de enlace: 'psiquiatría psicosomática'. Psiquiatria.com 2002; 6(1). (electronic publication) Available in URL: [http://www.psiquiatria.com/articulos/psiq_de_enlace/5680/].

21. Lozano M, Lobo A. Psychosomatic psychiatry: a Spanish proposal for a new denomination. J Psychosom Res 2005; 59(6): 451-452.

22. Wise MG, Rundell JR. Preface. In Wise MG, Rundell JR (eds.) Textbook of Consultation-Liaison Psychiatry: The Practice of Psychiatry in the Medically Ill. Washington: American Psychiatric Publishing; 2002. p. XV-XVI.

23. Levenson JL (Editor). Textbook of Psychosomatic Medicine. Washington DC: American Psychiatric Press Inc. 2005.

24. Bertolini C, Rigatelli M, Rizzardo R et al. Psychiatri di consultazione e collegamento (Consultation-liaison psychiatry). Ib Trattato Italiano di Psichiatria (Italian Textbook of Psychiatry), $2^{\text {nd }}$ Edition, Vol 3. Edited by Pancheri P, Cassano GB. Milan, Italy, Editions Masson, 1999. p. 3841-3871.

25. Lobo A. Philosophical humanism and empirical science: Spanish perspectives on Psychosomatics. Advances 1986; 3(4): 58-76.

26. Herzog T, Stein B, Nickel Th, Lobo A, Huyse F, Malt UF and the European Consultation Liaison Work- group (ECLW). Tratamiento de los trastornos 'psicosomáticos'. Cuestiones conceptuales y de 'coste-efectividad'. Trasfondo histórico y evidencia empírica desde los servicios (consultas) de salud mental españoles y alemanes. Cuadernos de Psicosomática 1994; 30: 12-27.

27. Engel GL. The need for a new medical model: a challenge for biomedicine. Science 1977; 196: 129-136.

28. Shepherd M. Introduction: The sciences and general psychopathology. In Shepherd M, Zangwill OL, (eds.) General psychopathology. Cambridge: Cambridge University Press; 1983. p. 1-4

29. Jaspers K. General Psychopathology. Manchester: Manchester University Press; 1963.

30. McHugh PR, Slavney PR (eds.). The perspectives of psychiatry (second edition). Baltimore \& London: The Johns Hopkins University Press; 1998. p. 16, p. 29, p. 69-70.

31. McHugh PR. A structure for psychiatry at the century's turn: the view from Johns Hopkins. J Roy Soc Med 1992; 85: 483-487.

32. Lobo A. Elucidating Mental Disorded in Liaison Psychiatry: The John Hopkins 'Perspectives'. J Psychosom Res 1996; 41(1): 7-11.

33. Lain Entralgo P. The therapy of the world in classical antiquity, Trans. Rather LJ, Sharp JM. New Heaven: Yale University Press; 1970.

34. Frank JD. Holistic medicine--a view from the fence. Johns Hopkins Med J 1981; 149(6): 222-227.

35. Von Uexküll T, Pauli HG. The mind-body problem in medicine. Adv Inst Health 1986; 3(4): 158-174.

36. Söllner W. What is left from the Early Psychosomatic Movement? Paper read at the $9^{\text {th }}$ Annual Scientific Meeting of the European Association of Consultation Liaison Psychiatry and Psychosomatics in Lausanne 2006.

37. Fox BH, Temoshok L. Conclusion. Advances 1986; 3(4): $175-179$.

38. Thorpe WH. Animal Nature and Human Nature. London: Methuen; 1974.

39. Margolis J. Persons and minds: the prospects of nonreductive materialism. Dordrecht, Holland, Boston: Reidel; 1977. (Boston studies in the philosophy of science: Synthese library; v. 121; v. 57).

40. Fink PJ. Response to the presidential address: is 'biopsychosocial' the psychiatric shibboleth? Am J Psychiatry 1988; 145: 1061-1067.

41. Shepherd M. Epidemiological perspective: psychosomatic medicine. Int J Epidemiol 1978; 3(7): 201. 
42. Granville-Grossman K. Mind and body. In Lader $\mathrm{MH}$, (eds.) Mental disorders and somatic illness. Handbook of psychiatry II. Cambridge: Cambridge University Press; 1983. p. 5-13.

43. Lobo A, Campos R. The contribution of epidemiology to psychosomatic medicine. Epidemiol Psichiatr Soc 1997; 6(1): 40-47.

44. Yates WR. Epidemiology of psychiatric disorders in medically ill patients. In Wise MG, Rundell J R (eds.) Textbook of Consultation-Liaison Psychiatry: The Practice of Psychiatry in the Medically Ill. Washington: American Psychiatric Publishing; 2002. p. 237-256.

45. Bynum WF. Psychiatry in its historical context. In Shepherd M, Zangwill OL, (eds.) Handbook of psychiatry I: General psychopathology. Cambridge: Cambridge University Press; 1983. p. 11-38.

46. Bynum WF. Psychosomatic. In Shepherd M, Zangwill OL, (eds.) Handbook of psychiatry I: General psychopathology. Cambridge: Cambridge University Press; 1983. p. 54-55.

47. World Health Organization. Psychosomatic disorders. Technical report series. Geneva: World Health Organization; 1964

48. Lipowski ZJ. What does the word 'psychosomatic' really mean? A historical and semantic inquiry. Psychosom Med 1984; 46(2): 153-171.

49. Lipowski ZJ. Psychosomatic medicine: past and present. Part II. Current state. Can J Psychiatry 1986; 31(1): 8-13.
50. Lobo A, Lobo-Escolar A. 'Enfermedades psicosomáticas'. La visión general de la Psiquiatría 'de enlace'. Tiempos Médicos 2003; 599: 17-24.

51. Lobo A, Saz P, Sarasola A, Bulbena A, DePablo J, Garcia-Camba E et al. Spanish perspective on enlarging a small specialty: the national research network for liaison psychiatry and psychosomatics. Psychosomatics 2007 JanFeb; 48(1): 46-53.

52. Kathol RG. Medical Psychiatry Units: The Wave of the Future. Gen Hosp Psychiatry 1994; 16(1): 1-3.

53. Campayo A, García-Moreno ME, Cuevas JM, Burillo-Traid C. Medicine-Psychiatry Units: 'Towards a model for the Spanish Sanitary System'. Eur J Psychiatry; (in press)

54. Huyse FJ, Stiefel FC (editors). Integrated Care for the Complex Medically Ill. Philadelphia: Elsevier; 2006.

55. Kathol RG, Saravay S M, Lobo A, Ormel J. Epidemiologic trends and costs of fragmentation. Med Clin North Am 2006; 90(4): 549-572.

Address of correspondence:

Dr. Antonio Lobo

Hospital Clínico Universitario

Servicio de Psiquiatría. Planta 3

Avda. San Juan Bosco, 15

50009 Zaragoza

SPAIN

Telephone \#: +34 976551167

Fax \#: +34 976765788

e-mail address: alobo@unizar.es 